\title{
A Study of Morphine-Induced Urinary Retention in Anesthetized Rats Capable of Micturition
}

\author{
Hitoshi KONTANI and Yoichi KAWABATA* \\ Department of Pharmacology. Hokuriku University, School of Pharmacy. \\ Kanagavva-machi, Kanazawa 920-11, Japan \\ Accepted May 13, 1988
}

\begin{abstract}
The nature of morphine-induced urinary retention was studied in anesthetized rats in which the bladder contraction accompanying micturition could be observed. Morphine $(0.1 \mathrm{mg} / \mathrm{kg}$, i.v.) prolonged the micturition interval and increased the level of micturition threshold. Morphine $(1 \mathrm{mg} / \mathrm{kg}$, i.v.) completely inhibited bladder contraction and bladder pressure was elevated until solution leaked from the penis, but the bladder pressure after inhibition by morphine ( 1 and $5 \mathrm{mg} / \mathrm{kg}$, i.v.) did not significantly rise over the peak pressure level during micturition before injection of morphine. The inhibitory effect of morphine ( 1 and $5 \mathrm{mg} /$ $\mathrm{kg}$, i.v.) was reversed by naloxone $(0.1 \mathrm{mg} / \mathrm{kg}$. i.v.). Morphine $(5 \mathrm{mg} / \mathrm{kg}$, i.v.) did not increase the pressure induced by infusion of solution from near the bladder neck to the urethra. After intracerebroventricular (i.c.v.) and intrathecal (i.t.) administration of morphine $(1 / \mathrm{g})$, the micturition interval was prolonged and the level of micturition threshold was increased. Morphine (5 $\mu$ g, i.c.v and i.t.) inhibited bladder contraction and naloxone ( $5 \mu \mathrm{g}$, i.c.v. and i.t.) reversed the inhibitory effect of morphine injected by the same administration route. From these results, urinary retention induced by systematically injected morphine was considered to result from inhibition of bladder function mediated via opioid receptors of the micturition centers in the supraspinal and spinal regions.
\end{abstract}

Morphine usually causes urinary retention at therapeutic doses when it is employed as an analgesic, and this is attributed to the inhibitory effects of morphine on both peripheral organs and the central nervous system (1). However, most of the experiments used to study the effects of morphine on urinary bladder contraction have been performed in urethra-cannulated rats, so that it was not possible to observe micturition and retention of urine (2-10). Recently, we (11-13) developed a method for recording the bladder contraction accompanying micturition in anesthetized rats, and using this method, we investigated the effects of various drugs. In the present experiments, we clarified the nature of the drug action related to urinary

\footnotetext{
* Present Address: Research Laboratories, Kotobuki Seiyaku Co.. Ltd., Sakaki-machi, Hanishina-gun, Nagano 389-06. Japan
}

retention.

\section{Materials and Methods}

The methods used for recording bladder contraction was described in our previous papers $(11,12)$. Male Wistar rats (weighing 250-350 g) were anesthetized with urethane $(1.0 \mathrm{~g} / \mathrm{kg}$, s.c.) and $\alpha$-chloralose $(25 \mathrm{mg} / \mathrm{kg}$. s.c.). The bladder was exposed through a midline incision in the abdomen and a needle $(1 / 4)$ attached to a silicone tube (O.D., 1.0 $\mathrm{mm}$ and I.D., $0.5 \mathrm{~mm}, 30-40 \mathrm{~cm}$ in length) was inserted into the bladder through the left ureter. In the present experiment, after ligation of the left ureter around the needle, the bladder was put back into the abdominal cavity and the incision was sutured. Bladder contraction was induced by infusion of Tyrode's solution lacking glucose into the bladder through the silicone tube at a constant rate $(0.6-0.8 \mathrm{ml} / 10 \mathrm{~min})$, and the pres- 
sure signals were measured by a pressure transducer (Nihon Kohden, LPU-0.1) connected to the silicone tube via a T-tube.

In order to study the effects of drugs on the resistance at the bladder outlet, pressure changes were measured when Tyrode's solution was flowing through it. The bladder was cut through the apex, and a needle (O.D., $3 \mathrm{~mm}$ ) was inserted near the bladder neck through the opening. The bladder was then separated from the prostate, and the bladder dome was ligated around the inserted needle near the bladder neck. A silicone tube was connected to the needle to infuse Tyrode's solution at a constant rate $(0.4-0.5 \mathrm{ml} / 10$ $\mathrm{min})$. The pressure signal was measured via a pressure transducer (Nihon Kohden, LPU0.1).

Intracerebroventricular (i.c.v.) and intrathecal (i.t.) injections were performed according to the methods described in previous papers $(12,13)$. For i.t. injection, a catheter (polyethylene tube, SP-8, Natsume) with a $5-\mu l$ volume was used. In the experiment to determine the antagonism between i.t.-injected morphine and naloxone, morphine was injected in a volume of $20 \mu l$, followed by $5 / \mu$ of artificial cerebrospinal fluid to flush out the catheter, and then naloxone solution in a volume of $25 \mu \mathrm{l}$ was injected via the catheter.

Drugs used were: morphine $\mathrm{HCl}$ (Takeda Chemical Industries, Ltd.) and naloxone $\mathrm{HCl}$ (a gift from Sankyo). Each drug was examined in at least 4 rats. All drug concentrations in this report are expressed as those of each respective salt.

\section{Results}

1) Inhibitory effects of morphine on bladder contraction and the antagonistic effect of naloxone: Before injection of morphine, the mean micturition interval was $5.6 \pm 0.5$ min (mean \pm S.E., $n=15$ ), and the mean bladder pressure at which the pressure rose steeply (micturition threshold) was $6.7 \pm 0.8$ $\mathrm{cmH}_{2} \mathrm{O}$ (mean \pm S.E., $\mathrm{n}=15$ ). After morphine $(0.1 \mathrm{mg} / \mathrm{kg}$, i.v.) injection, the micturition threshold was increased and the micturition interval was prolonged (Fig. 1). The percentage of micturition threshold or the mean interval after morphine $(0.1 \mathrm{mg} / \mathrm{kg}$, i.v.) injection relative to those before injection was $186 \pm 25$ or $270 \pm 37$ (mean \pm S.E., $n=4$ ), respectively. Morphine (1 mg/kg, i.v.) completely inhibited
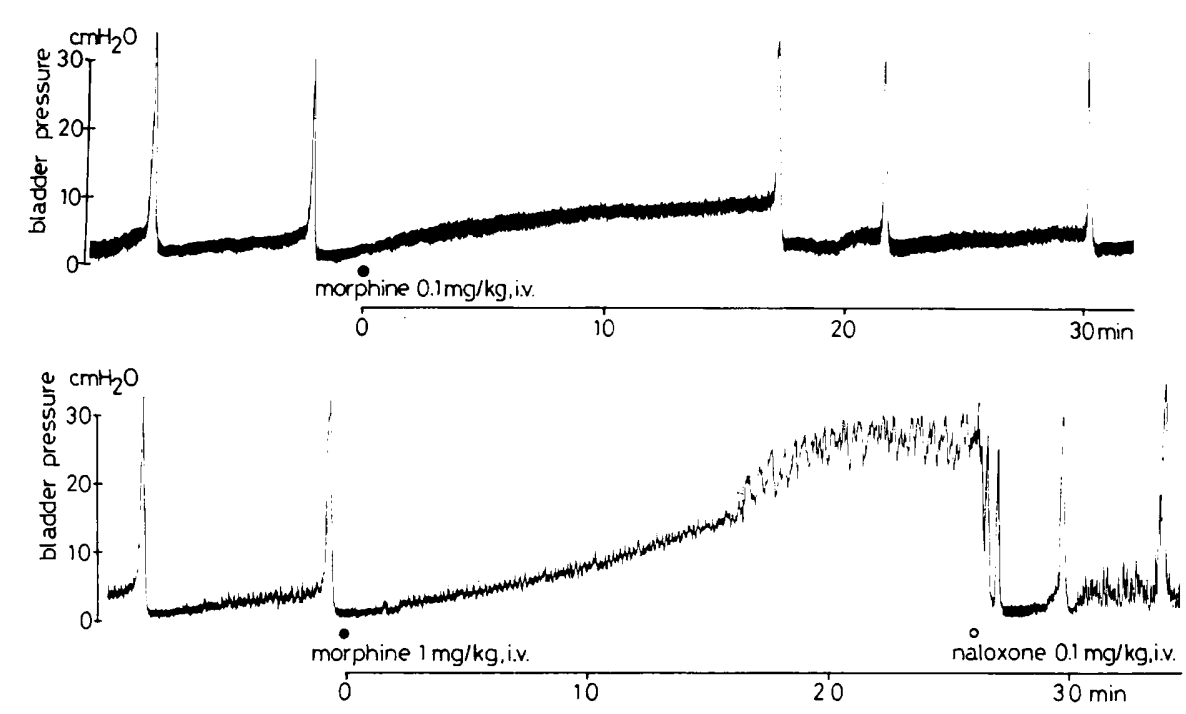

Fig. 1. The inhibitory effects of morphine on urinary bladder contraction and the antagonistic effect of naloxone on the inhibition of bladder contraction in anesthetized rats. The bladder contraction was induced by infusion of Tyrode's solution into the bladder. Vertical bar: bladder pressure. Horizontal bar: time after morphine injection. The solid circle and the open circle indicate the injection of morphine and naloxone, respectively. 
bladder contraction, and solution leaked from the penis when bladder pressure was elevated to almost the peak pressure level during micturition before injection of morphine. After injection of morphine ( $5 \mathrm{mg} / \mathrm{kg}$, i.v.), the bladder pressure at which solution leaked from the penis after inhibition of bladder contraction did not significantly rise over the peak pressure level before its injection. The percentages of mean bladder pressure at which solution leaked from the penis after i.v. injection of morphine at $1 \mathrm{mg} / \mathrm{kg}$ and $5 \mathrm{mg} / \mathrm{kg}$ relative to the peak pressure before morphine injection was $85 \pm 8$ (mean \pm S.E., $n=5$ ) and $111 \pm 7$ $(n=4)$, respectively. When naloxone $(0.1 \mathrm{mg} /$ $\mathrm{kg}$, i.v.) was injected after the bladder contraction was completely inhibited by morphine ( 1 and $5 \mathrm{mg} / \mathrm{kg}$, i.v.) and high bladder pressure was maintained for at least $5 \mathrm{~min}$, the in hibitory effect of morphine was immediately and completely reversed (Fig. 1).

2) Effects of morphine and naloxone on the resistance in the bladder outlet: When Tyrode's solution was infused through the cannula inserted from the apex of the bladder near the bladder outlet, the leakage of solution from the bladder outlet began at a pressure of $24 \pm 2 \mathrm{cmH}_{2} \mathrm{O}$, and the pressure fell to $11 \pm 2$ $\mathrm{cmH}_{2} \mathrm{O}$ (mean \pm S.E., $\mathrm{n}=4$ ). The pressure change continued during infusion of solution. Morphine $(5 \mathrm{mg} / \mathrm{kg}$, i.v.) slightly changed the pattern of pressure change, but there was no increase in the pressure at which the leakage of solution began. There was one experiment in which the amplitude of the pressure change after morphine injection was small for about $5 \mathrm{~min}$. After injection of naloxone $(0.1 \mathrm{mg} / \mathrm{kg}$. i.v.), the pattern of pressure change was restored to that before injection of morphine (Fig. 2).

3) Inhibitory effect of i.c.v. or i.t. injection of morphine on bladder contraction and the antagonistic effect of naloxone: After i.c.v. or i.t. injection of morphine $(1 \mu \mathrm{g})$, the bladder contraction was completely inhibited in two out of four rats. In the other rats after i.c.v. administration of morphine $(1 \mu \mathrm{g})$, the bladder pressures were gradually increased almost to the peak pressure level before its administration until micturition took place; and after i.t. administration of morphine $(1 \mu \mathrm{g})$, the level of micturition threshold was 2.6 times as high as that before its administration. In two rats, the micturition interval after i.c.v. or i.t. administration of morphine $(1 \mu \mathrm{g})$ was 2.1 or 2.3 times as long as that before each administration, respectively. With both i.c.v. and i.t. injection of morphine ( $5 \mu \mathrm{g})$, the bladder contraction was completely inhibited in all four rats. The pressures after inhibition of bladder contraction by morphine ( $5 \mu \mathrm{g}$, i.c.v. and i.t.) were increased to the levels of $84 \pm 1$ and $96 \pm 2 \%$ of the peak pressure before each administration, respectively. The inhibitions induced by morphine ( $5 \mu \mathrm{g}$, i.c.v. or i.t.) were reversed by naloxone ( $5 \mu \mathrm{g}$ ) by the same administration route. Though the bladder contractions restored by $5 \mu \mathrm{g}$ of naloxone, i.c.v., continued, those restored by $5 \mu \mathrm{g}$ of naloxone, i.t., were arrested and 10-20 $\mu \mathrm{g}$ of naloxone, i.t., were necessary to reverse the inhibitory effects of morphine (5 $\mu$ g, i.t.) (Fig. 3). The dose of i.v.-injected naloxone which was able to completely reverse the inhibitory effect of $5 \mu \mathrm{g}$ of i.c.v- or i.t.-injected morphine was $0.1 \mathrm{mg} / \mathrm{kg}$ or $1 \mathrm{mg} / \mathrm{kg}$, respectively (Fig. 4).

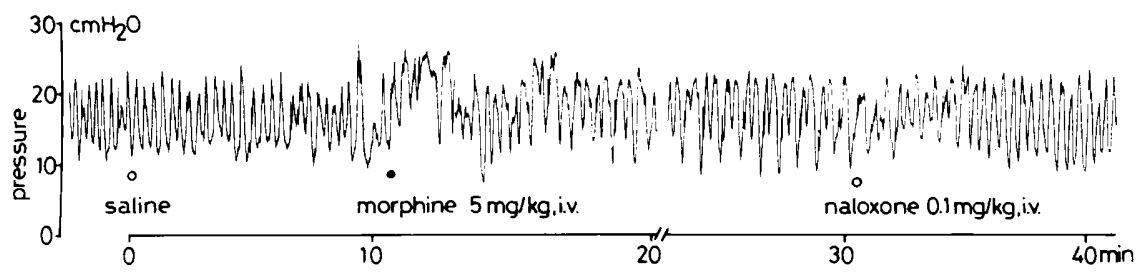

Fig. 2. The pressure induced by infusion of Tyrode's solution from the neighborhood of the bladder outlet to the urethra and the effects of morphine and naloxone on the pressure in anesthetized rats. Tyrode's solution was infused at a constant rate $(0.4-0.5 \mathrm{ml} / 10 \mathrm{~min})$ through the cannula inserted from the apex of the bladder. The bladder dome was ligated on the cannula near the bladder neck. Horizontal bar: time after saline injection. The open circles indicate the injection of saline or naloxone, and the solid circle indicates the injection of morphine. 

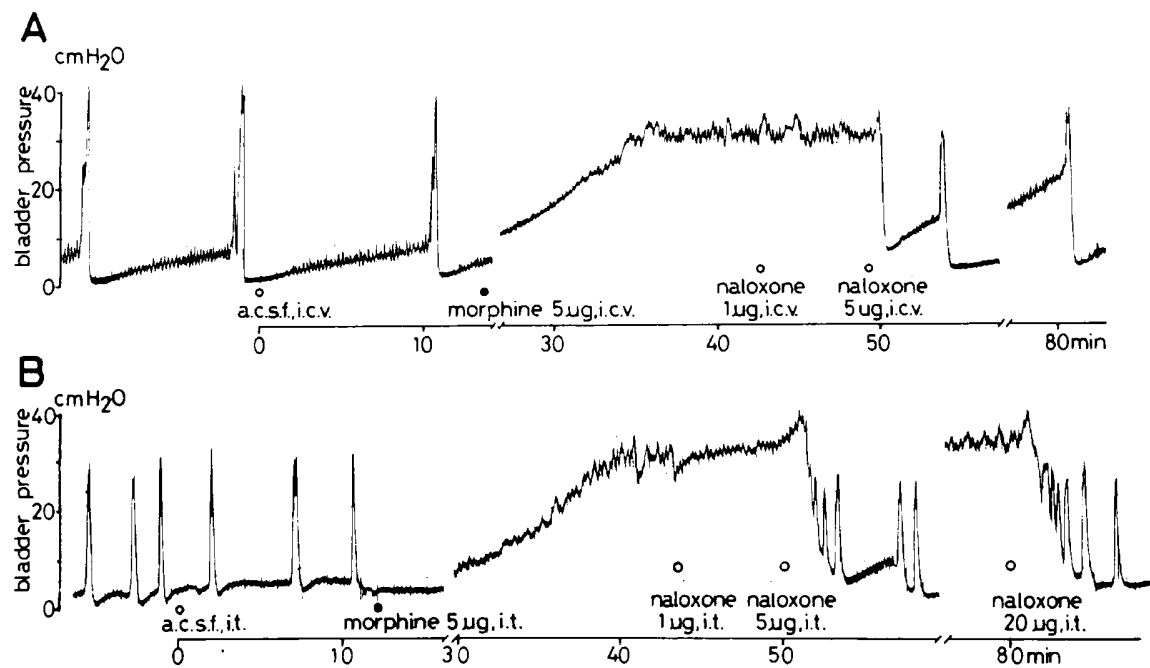

Fig. 3. The effects of intracerebroventricular (i.c.v.. A) or intrathecal (i.t., B) injection of morphine on urinary bladder contraction and the antagonistic effect of i.c.v. or i.t. injection of naloxone on inhibition produced by i.c.v. or i.t. injection of morphine, respectively. Vertical bar: bladder pressure. Horizontal bar: time after i.c.v. or i.t. injection of artificia! cerebrospinal fluid (a.c.s.f.). The open circles indicate i.c.v. or i.t. injection of a.c.s.f. or naloxone, and the solid circles indicate i.c.v. or i.t. injection of morphine.
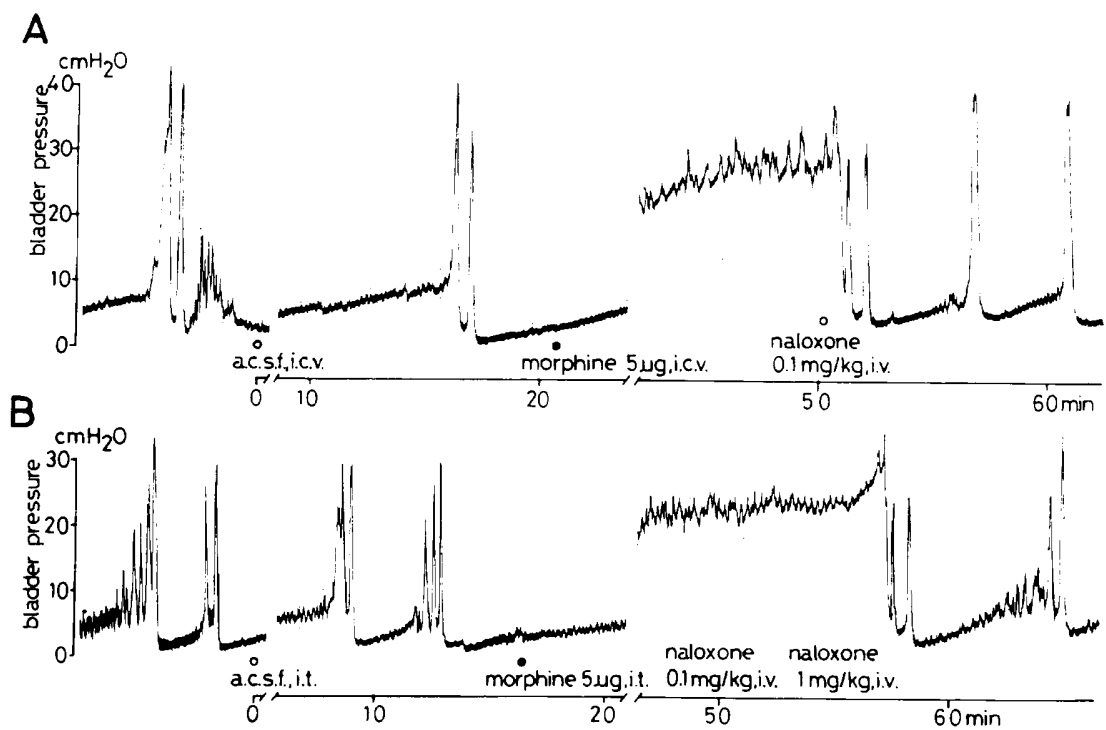

Fig. 4. The antagonistic effects of i.v. injection of naloxone on the inhibition of urinary bladder contraction by intracerebroventricular (i.c.v.. A) or intrathecal (i.t., B) injection of morphine. Vertical bar: bladder pressure. Horizontal bar: time after i.c.v. or i.t. injection of artificial cerebrospinal fluid (a.c.f.s.) The open circles indicate intracerebroventricular (i.c.v.) or intrathecal (i.t.) injection of a.c.s.f. or i.v. injection of naloxone, and the solid circles indicate i.c.v. or i.t. injection of morphine.

\section{Discussion}

The inhibitory effects of morphine on rat bladder contraction have been widely studied, and it has been clarified that its main sites of action are the supraspinal and spinal micturition centers and that the opioid receptors involved are of the mu and delta subtypes 
(2-10). In the brainstem reticular formation of the mid brain, pons and medullaoblongata, detrusor motor centers are located; and in the sacral parasympathetic nucleus of segments $S_{2}$ to $S_{4}$, parasympathetic preganglionic cell bodies innervating the bladder and internal sphincter are found (14). In order to study the inhibitory effects of morphine on the bladder motility via the opioid receptors of these micturition centers in the supraspinal and spinal regions, i.c.v. or i.t. injection of morphine were investigated. Morphine $(0.1 \mathrm{mg} /$ $\mathrm{kg}$, i.v.) caused the prolongation of micturition interval and the increase in the micturition threshold, and morphine (1 $\mathrm{mg} / \mathrm{kg}$, i.v.) completely inhibited the bladder contraction (Fig. 1). After i.c.v or i.t. injection of morphine (1 and $5 \mu \mathrm{g}$ ), inhibition of the bladder motility similar to that induced by i.v.-injected morphine appeared. A blocking effect of endogenous opioids on transmission in the pelvic ganglia has been described $(15,16)$. In this model, hexamethonium $\left(\mathrm{C}_{6}, 5 \mathrm{mg} / \mathrm{kg}, \mathrm{i} . \mathrm{v}.\right)$ increased the frequency of bladder contraction without increase in the micturition threshold. Aithough $\mathrm{C}_{6}(20 \mathrm{mg} / \mathrm{kg}$, i.v. $)$ interrupted micturition, small contractions appeared (11). The prolongation of micturition interval and the increase in the micturition threshold induced by i.v.-injected morphine would not result from the blockage of transmission in the pelvic ganglia. After inhibition of bladder contraction by i.v. injected-morphine, the pressure did not significantly rise over the peak pressure before injection of morphine (Fig. 1). The pressure induced by infusion of solution from near the bladder outlet to the urethra was not increased by morphine ( $5 \mathrm{mg} / \mathrm{kg}$, i.v.) (Fig. 2). These results did not suggest the increase in the tone of the muscle around the bladder outlet by systematically injected morphine. From these results, it is suggested that the urinary retention induced by morphine results from the inhibition of bladder function due to the inhibitory effects of morphine on the micturition centers in the central nervous system. The finding that morphine (1 $\mathrm{mg} / \mathrm{kg}$, i.v.) abolished the efferent discharges also suggests the nature of the active site (our unpublished data). The inhibitory effects of morphine (1 and $5 \mathrm{mg}$ / $\mathrm{kg}$, i.v.) were completely reversed by naloxone
$(0.1 \mathrm{mg} / \mathrm{kg}$, i.v.). Since the degree of uptake of naloxone in the rat brain is approximately 11 times that of morphine (17), the concentrations of morphine and naloxone in the central nervous system would not be significantly different. The doses of i.c.v.- and i.t.injected morphine which were able to inhibit the bladder contraction were $5 \mu \mathrm{g}$, and the dose of naloxone which was able to reverse the inhibitory effects of i.c.v.- or i.t.-injected morphine was also $5 \mu \mathrm{g}$ (Fig. 3). However, a higher dose of i.v.-injected naloxone was necessary to reverse the inhibitory effect of i.t.-injected morphine $(5 \mu \mathrm{g})$ than that of i.c.v. injectedmorphine (5 $\mu \mathrm{g})$ (Fig. 4). Systematically injected naloxone would easily penetrate into the micturition center in the supraspinal region, as compared with that in the spinal region.

\section{References}

1 Jaffe, J.H. and Martin, W.R.: Opioid analgesics and antagonists. In The Pharmacological Basis of Therapeutics (7th edition), Edited by Gilman. A.G., Goodman, L.S., Rall, T.W. and Murad, F.. p. 491-531, MacMillan Publishing Company, New York (1985)

2 Dray, A. and Metsch, R.: Inhibition of urinary bladder contractions by a spinal action of morphine and other opioids. J. Pharmacol. Exp. Ther. 231, 254-260 (1984)

3 Dray, A. and Metsch, R.: Opioid receptor subtypes involved in the central inhibition of urinary bładder motility. Eur. J. Pharmacol. 104, 47-53 (1984)

4 Dray, A. and Metsch, R.: Morphine and the centrally-mediated inhibition of urinary bladder motility in the rats. Brain Res. 297, 191-195 (1984)

5 Dray, A. and Metsch, R.: Opioids and central inhibition of urinary bladder motility. Eur. J. Pharmacol. 98, 155-156 (1984)

6 Dray, A. and Metsch, R.: Spinal opioid receptors and inhibition of urinary bladder motility in vivo. Neurosci. Lett. 47, 81-84 (1984)

7 Dray, A.: The rat urinary bladder. A novel preparation for the investigation of central opioid activity in vivo. J. Pharmacol. Methods 13, 157165 (1985)

8 Dray, A., Numan, L. and Wire, W.: Central $\delta$ opioid receptor interactions and the inhibition of reflex urinary bladder contraction in the rat. $\mathrm{Br}$. J. Pharmacol. 85, 717-726 (1985)

9 Sillén, $U$. and Rubenson, A.: Central and peri- 
pheral motor effects of morphine on the rat urinary bladder. Acta Physiol. Scand. 126, 181187 (1986)

10 Sheldon, R.J., Nunan, L. and Porreca, F.: Mu antagonist properties of kappa agonists in a model of rat urinary bladder motility in vivo. J. Pharmacol. Exp. Ther. 243, 234-240 (1987)

11 Kontani, H., Kobayashi, H., Kawabata, Y. and Koshiura, R.: In vivo effects of drugs that act on the autonomic nervous system on the urinary bladder contraction accompanying micturition. Japan. J. Pharmacol. 43, 43-51 (1987)

12 Kontani, H., Kawabata, Y. and Koshiura, R.: In vivo effects of $\gamma$-aminobutyric acid on the urinary bladder contraction accompanying micturition. Japan. J. Pharmacol. 45, 45-53 (1987)

13 Kontani, H., Kawabata, Y. and Koshiura, R.: The effect of baclofen on the urinary bladder contraction accompanying micturition in anesthetized rats. Japan. J. Pharmacol. 46, 7-15
(1988)

14 Fletcher, T.F. and Bradley, W.E.: Neuroanatomy of the bladder-urethra. J. Urol. 119, 153-160 (1978)

15 De Groat, W.C., Kawatani, M., Hisamitsu, T., Lowe, I., Morgan, C., Roppolo, J., Booth, A.M. Nadelhaft, I., Kuo, D. and Thor, K.: The role of neuropeptides in the sacral autonomic reflex pathways of the cat. J. Auton. Nerv. Syst. 7, 339350 (1983)

16 Maggi, C.A. and Meli, A.: The role of neuropeptides in the regulation of the micturition reflex. J. Auton. Pharmacol. 6, 133-162 (1986)

17 Misra, A.L., Pontani, R.B., Vadlamani, N.L. and Mule, S.J.: Physiological disposition and biotransformation of (allyl- $1^{\prime}, 3^{\prime}-{ }^{14} \mathrm{C}$ ) naloxone in the rat and some comparative observations on nalorphine. J. Pharmacol. Exp. Ther. 196, 257$269(1976)$ 